\title{
The Prediction Model for Low Birth Weight in Batang District, Central Java, Indonesia by Martha Irene Kartasurya
}

File name: $27 . p d f(76.22 \mathrm{~K})$

Word count: 2803

Character count: 14189 


\title{
The Prediction Model for Low Birth Weight in Batang District, Central Java, Indonesia
}

\author{
Martha Irene_Kartasurya ${ }^{1, *}$, Yudhy Dharmawan ${ }^{2}$, Bagoes Widjanarko ${ }^{3}$, and Novia Handayani ${ }^{4}$ \\ 1 Public Health Nutrition Department, Faculty of Public Health, Diponegoro University, 50275, Indonesia \\ ${ }^{2}$ Biostatistics and Population Study Dep 1 tment, Faculty of Public Health, Diponegoro University, 50275, Indonesia \\ ${ }^{3}$ Health Education and Behavioral Science Depa 1 nent, Faculty of Public Health, Diponegoro University, 50275, Indonesia \\ ${ }^{4}$ Master's Program in Health Promotion, Faculty of Public Health, Diponegoro University, 50275, Indonesia
}

\begin{abstract}
Bad1 1round: In Indonesia, the prevalence of low birth weight, was high (10.7\%). Batang District had the highest low birth weight prevalence in Central Java. Maternal and environmental factors are the strongest factors, therefore these risk factors were investigated, and prediction model for birth weight was designed. Method: This case-control study was done on 163 low birth weight $(<2500 \mathrm{~g})$ as cases and 163 normal weight $(\geq 2500 \mathrm{~g})$ babies and their mothers as controls. The cases were all of the singleton birth low birth weight babies aged $<6$ months in Batang District. The controls were normal birth weight and matched for gender, age and village. Data were collected by interviews and review of maternal and child health handbooks. The risk factors which were investigated including mother's characteristics, nutritional status, health condition, behavioral factor, environmental factor, and health service factor. Among the most important risk factors, the multiple linear regressions were run to find the best prediction model. Results: The significant risk factors of birth weight were anemia $(O R=2.85)$, lack of ante natal visits $(O R=2.24)$, hypertension $(O R=2.09)$, maternal age $<20$ years or $\geq 35$ years $(O R=2.07)$, disease/maternal disorders during pregnancy $(O R=1.85)$, abortion history $(O R=1.82)$, Low MUAC $(O R=1.58)$ and low protein intake $(O R=1.50)$. The best predictors were hemoglobin levels, the completeness of ante natal visits, MUAC and mother's age at pregnancy. Conclusion: The most important factors which can predict the birth weight of the babies are maternal age, hemoglobin levels, ANC frequency and Mid Upper Arm Circumference.
\end{abstract}

Keywords: Low Birth Weight, Anemia, Mid-Upper Arm Circumference (MUAC), Antenatal Visit.

\section{INTRODUCTION}

Globally, 60 to $80 \%$ neonatal deaths were associated with low birth weight (LBW), and $96.5 \%$ of them were from developing countries. ${ }^{1}$ Based on 2012 Indonesian Demographic Health Survey, LBW direct contribution to neonatal mortality in Indonesia was $21.3 \%$, while the rest problems were still related to LBW, such as intra-uterine fetal death, birth asphyxia, respiratory distress, and neonatal sepsis.

In Central Java Province, LBW was the main cause of infant deaths $(80 \%)$. Since 2006, the IMR of Central Java Province has increased over the years. The absolute number of early neonatal deaths in Central Java Province was also the highest in Indonesia. ${ }^{2}$ Based on WHO reports and some other studies in Indonesia, factors related to mother's condition during pregnancy was the main cause of LBW. ${ }^{3}$ Those factors could be classified into mother's characteristics, nutritional statuses, health conditions, behavioral factors, environmental factors, and health service factors.

"Author to whom correspondence should be addressed.
Previous studies have been conducted on maternal factors such as in Nigeria, ${ }^{4}$ India ${ }^{5}$ and Pakistan ${ }^{6}$ and even the history or maternal early life factor ${ }^{7}$ and maternal genetics. ${ }^{8}$ Maternal age was an important factor as teenage pregnancy also contributes to be the second lead to low birth weight. ${ }^{9}$ Another study includes smoking as the risk factor for low birth weight. ${ }^{10}$ In this study, passive smoking was included as the risk factors, because even though smoking mother rate was very low in this area of study, the passive smoking rates were very high. However, not many studies have combined maternal and environmental factors on LBW at the same time.

The risk factors for low birth weight were different based on the areas of study. ${ }^{11,12}$ In Indonesia, the risk for low birth weight in the northern part of Central Java, especially in Batang, which has the highest rate of low birth weight has never been studied before. This study needs to be done to plan the intervention that can be done to prevent low birth weight. ${ }^{13}$

Almost all of those factors are preventable, thus the knowledge of the most important factors are needed. Then based on these important variables of pregnant mothers, the best regression

1936-6612/2017/23/3442/003 doi:10.1166/asl.2017.9123 
model can be made to predict the birth weight. This prediction model for each pregnant mother will be important to target the intervention program to prevent low birth weight babies.

\section{METHOD}

The maternal risk factors for LBW were investigated in a casecontrol study conducted in Batang regency. Batang regency was selected as it has the highest prevalence of low birth weight in Central Java province. Central Java Province has the highest absolute number of low birth weight cases. Total sampling techniques were used for selecting the cases. The cases were 163 mothers and their babies aged less than six months, who were born as low birth weight $(<2500 \mathrm{~g})$ and the controls were 163 mothers and their babies who were born at a normal weight $(\geq 2500 \mathrm{~g})$. Cases and controls were matched for age and gender.

Data were collected by interviews using structured questionnaires to the mothers and secondary data from the records in maternal and child handbook of each baby. The food consumption data were collected by semi-quantitative food frequency questionnaires. The subjects asked were about their food consumption during their pregnancies. The risk factors which were investigated were:

(1) Demographical characteristics: maternal age at risk $(<20$ years or $\geq 35$ years), high parity $(>2)$, low income ( $<$ Rp.1.270.000, regional minimal wages), low education level ( $<9$ years),

(2) Nutritional status: low-mid upper arm circumference (MUAC $<23.5 \mathrm{~cm})$ ), low weight gain during pregnancy $(<9 \mathrm{~kg})$, anemia $(\mathrm{Hb}<11 \mathrm{~g} / \mathrm{L})$,

(3) Health conditions included infectious disease and noninfectious disease such as hypertension, and hyper-emesis gravidarum,

(4) Behavioral factors such as low nutrient intake, and lack of antenatal care visit,

(5) Environmental factors: cigarettes exposure in the household and

(6) Health service factors: low quality of ante natal care (not fulfilling National ANC program of 1, 1, and 2 visits during the 1 st, 2nd and 3rd trimester respectively for the normal pregnancy, without any complications/problems.

Data analysis was conducted by cross tabulation and Odd Ratio calculation of each risk factor. Variables which show Odd Ratios $>2$, were included in the linear regression models as continuous variables, with birth weight as the dependent variable. The best prediction model was chosen based on the simplest models which have the highest $R$-squared.

This study has been approved by the Faculty of Public Health, Diponegoro University Ethical Committee (No. 194/EC/FKM/2015) and therefore been performed by the ethical standards laid down in the 1964 Declaration of Helsinki and its later amendments. All subjects gave their informed consent before their inclusion in the study.

\section{RESULTS}

The subjects were from all over the area of Batang regency. In this study, the subjects were generally of low socioeconomic status. Table I shows the characteristics of the subjects.

The Odd Ratio for each risk factors was calculated and presented in Table II. This table shows that maternal age, anemia,
Table I. Characteristics of the mothers.

\begin{tabular}{lccc}
\hline & LBW & & NBW \\
\cline { 2 - 2 } Variables & Mean \pm SD & & Mean \pm SD \\
\hline Maternal age (years) & $26.2 \pm 7.10$ & & $26.9 \pm 6.23$ \\
Parity & $1.4 \pm 0.95$ & & $1.4 \pm 0.75$ \\
Education levels (years) & $8.4 \pm 2.93$ & & $8.4 \pm 2.93$ \\
Family income (thousand Rupiahs) & $1.800 \pm 900$ & & $2.100 \pm 1.200$ \\
MUAC (cm) & $24.0 \pm 2.57$ & & $24.8 \pm 2.60$ \\
Weight gain (kg) & $8.7 \pm 4.60$ & & $10.1 \pm 5.01$ \\
Hemoglobin levels (g/dL) & $10.8 \pm 1.28$ & & $11.1 \pm 1.17$ \\
Energy adequacy levels (\%) & $82.5 \pm 26.36$ & & $89.3 \pm 35.20$ \\
Protein adequacy levels (\%) & $110.8 \pm 45.76$ & & $85.0 \pm 37.37$ \\
Iron adequacy levels (\%) & $25.9 \pm 12.26$ & & $30.7 \pm 19.15$ \\
Zn adequacy levels (\%) & $10.6 \pm 5.02$ & & $12.0 \pm 6.14$ \\
Ante natal visits (times) & $2.5 \pm 0.5$ & \\
Cigarettes' exposure & $1.1 \pm 0.6$ & \\
$\quad$ (numbers of cigarettes/day) & & \\
\hline
\end{tabular}

disease during pregnancy, ANC completeness and housing condition were the risk factors for low birth weight.

The best prediction model for the birth weight of the babies was Birth Weight $=\mathbf{7 4 1 . 3 3}+\mathbf{2 6 8 . 1 2 2}$ (Maternal Age Group) + 24.732 (Hemoglobin levels) + 43.476 (MUAC) + 61.556 (Completeness of ANC). In this model, maternal age group was defined 0 if it was at risk ( $<20$ or $>35$ years) or 1 if not at risk (20-35 years) and completeness of ANC was 0 if it was not complete and 1 is it was complete. Hemoglobin levels were measured in $\mathrm{g} / \mathrm{dL}$ and MUAC were measured in centimeters.

\section{DISCUSSIONS}

Many studies showed that maternal characteristics associated with LBW. These features include, among maternal age less than 20 years old or older than 31 years old $(\mathrm{OR}=1.74$ and 1.80 respectively), low education $(\mathrm{OR}=2.0)$, and low income $(\mathrm{OR}=$ 1.7). ${ }^{14}$ This study used 35 years as the cut off for late maternal age and combined the two age groups as one. Thus this maternal age factor shows a stronger risk factor compared to the other studies. One explanation of the high prevalence of low birth weight among those aged less than 20 years old could be that the maternal growth is not fully complete. On the other hand, pregnancies in women over 31 years old might have impaired

Table II. The odd ratios of the maternal and environmental factors.

Maternal and environmental factors

Maternal age at risk

( $<20$ or $>35$ years)

Low family income

Low education

Low MUAC

Anemia

Low weight gain

Disease during pregnancy

Hipertension

Low energy adequacy

Low protein adequacy

Low zinc consumption

Low iron consumption

ANC completeness

Cigarette exposure

Cigarette exposure
Housing condition

\begin{tabular}{ccc}
$p$-value & OR & Cl \\
\hline $\mathbf{0 . 0 1 1}$ & $\mathbf{1 . 9 5}$ & $\mathbf{1 . 1 6 - 3 . 3 6}$ \\
& & \\
0.060 & 1.57 & $0.98-2.55$ \\
0.885 & 1.03 & $0.59-1.86$ \\
0.050 & 1.59 & $0.99-2.55$ \\
$\mathbf{0 . 0 0 0}$ & $\mathbf{2 . 9}$ & $\mathbf{1 . 7 3 - 4 . 8 4}$ \\
0.1573 & 1.4 & $0.88-2.24$ \\
$\mathbf{0 . 0 2 2}$ & $\mathbf{1 . 7 6}$ & $\mathbf{1 . 0 8 - 2 . 9 1}$ \\
0.108 & 2 & $0.86-4.94$ \\
0.416 & 1.21 & $0.76-1.93$ \\
0.289 & 1.29 & $0.81-2.08$ \\
0.254 & 1.30 & $0.83-2.07$ \\
$>0.99$ & 1 & $0.63-1.58$ \\
$\mathbf{0 . 0 0 0}$ & $\mathbf{2 . 4 2}$ & $\mathbf{1 . 5 1 - 3 . 9 5}$ \\
0.519 & 0.84 & $0.50-1.41$ \\
$\mathbf{0 . 0 0 3}$ & $\mathbf{2 . 8 5}$ & $\mathbf{1 . 7 3 - 4 . 8 4}$
\end{tabular}


intrauterine growth due to placental insufficiency or inadequate gestational duration. ${ }^{15}$

Maternal nutritional status which can be measured by midupper arm circumference and weight gain during pregnancy may have an effect on low birth weight. A study in Ethiopia showed that mothers with MUAC less than $23 \mathrm{~cm}$ have a higher risk of delivering an $\mathrm{LBW}$ infant $(\mathrm{OR}=1.6) .{ }^{16}$ In this study, we used $23.5 \mathrm{~cm}$ as the cut off for low MUAC as the risk for LBW, which probably explained why the OR was slightly lower compared to the study in Ethiopia. Maternal MUAC during pregnancy which is representing the situation prior to pregnancy is reflecting the maternal storage of energy.

The environment may affect the risk of having an LBW infant. Second-hand smoking is very common in Indonesia as most men smoke tobacco. A study of maternal exposure to secondhand smoking reported that second-hand smoking during pregnancy was significantly associated with increased odds of LBW $(\mathrm{OR}=1.56) .{ }^{17}$ Nicotine exposures are associated with LBW. Carbon monoxide (CO) from the smoke forms carboxyhemoglobin $(\mathrm{COHb})$, which results in the inhibition of oxygen transfer from maternal to fetal tissues. Nicotine also raises maternal blood pressure and heart rate, which is followed by the decrease in uterine blood flow. These may affect the fetal growth and may result in low birth weight. ${ }^{18,19}$ However, in this study, cigarette's exposure which was defined as passive smoking was not proven as the risk factor of low birth weight. It could be that almost all of the subjects were exposed to cigarette's smoke.

Anemia had been found to be a strong risk factor for low birth weight and prematurity based on previous studies. ${ }^{20,21}$ The biological mechanism which may result in low birth weight is through hypoxia, which causes maternal and fetal stress and this condition leads to the production of Corticotropin-releasing Hormone $(\mathrm{CRH}) . \mathrm{CRH}$ then raises the fetal cortisol production which may constrain the fetal growth. ${ }^{22}$

Housing condition was not included in the model, as in practice, it is difficult to find the housing condition during the ante natal visits to the midwives. Having disease during pregnancy become non-significant if the other variables included in the model, thus, we did not include in the final model. The best prediction model gave the best $R$-squared values compared to the other models.

\section{CONCLUSION}

It was concluded that the most important factors which can predict the birth weight of the babies were maternal age, hemoglobin levels, ANC frequency and Mid Upper Arm Circumference. It is recommended that the intervention to prevent low birth weight baby deliveries should be focused on increasing the age of first pregnancy, improving $\mathrm{Hb}$ level and nutritional status prior to pregnancy and improves ANC compliance.

\section{Conflict of Interest}

The authors have no conflict of interest.

Acknowledgments: Special thanks to the students who collected data on the field, midwives, health workers, health cadres, and Local Health Office in Batang Districts. This study was funded by Indonesian Ministry of Research, Technology and Higher Education.

\section{References and Notes}

1. WHO, Care of the preterm and/or low-birth-weight newborn. WHO, (2016), http://www.who.int/maternal_child_adolescent/topics/newborn/care_of _preterm/en/.

2. Ministry of Health, Indonesia. Indonesia Demographic and Health Survey (IDHS) 2012, Statistic Indonesia, National Population and Family Planning Board, Ministry of Health, Measure DHS, ICF International, Jakarta, Indonesia (2013).

3. WHO, Low Birth Weight: Country, Regional, and Global Estimates, WHO, (2009), http://whqlibdoc. who.int/publications/2004/9280638327.pdf, Accessed on March 12, 2014.

4. J. O. Awoleke, Arch. Gynecol. Obstet. 285, 1 (2012)

5. S. Mumbare, G. Maindarkar, R. Darade, S. Yenge, M. Tolani, and K. Patole, Indian Pediatr. 49, 25 (2012)

6. N. Khan and M. Jamal, J. Coll. Physicians Surg. Pak. 13, 25 (2003).

7. A. R. Gavin, K. G. Hill, J. D. Hawkins, and C. Maas, J. Adolesc. Heal. 2011 49, 166 (2011).

8. H. Yaghootkar and R. M. Freathy, Curr. Opin. Clin. Nutr. Metab. Care 2012 , 15, 258 (2012), DOI:10.1097/MCO.0b013e328351f543.

9. S. N. Partington, D. L. Steber, K. A. Blair, and R. A. Cisler, Perspect Sex Reprod. Health 41, 101 (2009).

10. H. Phung, A. Bauman, T. V. Nguyen, L. Young, M. Tran, and K. Hillman, Eur. J. Epidemiol. 18, 235 (2003)

11. P. R. Coutinho, J. G. Cecatti, F. G. Surita, J. P. De Souza, and S. S. De Morais, Rev. Assoc, Med. Bras. 55, 692 (2009)

12. J. E. Siza, Tanzan J. Health Res. 10, 1 (2008)

13. S. Redding, E. Conrey, K. Porter, J. Paulson, K. Hughes, and M. Redding, Matern. Child Health J. 19, 643 (2014)

14. J. Dickute, Z. Padaiga, V. Grabauskas, R. J. Nadisauskiene, V. Basys, and A. Gaizauskiene Medicina (Kaunas) 40, 475 (2004).

15. B. A. Thomre, J. Naik, and S. Rajderkar, International Journal of Recent Trends in Science And Technology 5, 03 (2012).

16. A. Nega, Y. Berhane, and A. Worku, Plos ONE 7, e 39957 (2012), DOI: 10.1371/journal.pone.0039957.

17. Y. S. Khader, N. Al-Akour, I. M. Alzubi, and I. Lataifeh, Maternal and Child Health Journal 15, 453 (2011)

18. D. S. Lambers and K. E. Clark, The maternal and fetal physiologic effects of nicotine, Seminars in perinatology 1996 (1996), Vol 20, pp. 115-126.

19. G. Salmasi, R. Grady, J. Jones, S. Mc Donald, Acta Obstetricia et Gynecologica Scandinavica Scandinavica 89, 423 (2010).

20. A. Levy, D. Fraser, M. Katz, M. Mazor, and E. Sheiner, European Journal of Obstetrics, Gynecology, and Reproductive Biology 122, 182 (2005).

21. Q. Zhang, C. V. Ananth, Z. Li, and J. C. Smulian, International Journal of Epidemiology 38, 1380 (2009).

22. L. Allen, The Journal of Nutrition 131, 581 (2001). 


\section{The Prediction Model for Low Birth Weight in Batang District, Central Java, Indonesia}

ORIGINALITY REPORT

2

SIMILARITY INDEX
$0 \%$

INTERNET SOURCES
$0 \%$

PUBLICATIONS
$2 \%$

STUDENT PAPERS

PRIMARY SOURCES

Exclude quotes

Off

Exclude bibliography

Off
Exclude matches

$<2 \%$ 